\title{
Light-weight Intermetallic Titanium Aluminides - Status of Research and Development
}

\author{
Helmut Clemens ${ }^{1, a}$ and Wilfried Smarsly ${ }^{2, b}$
}

${ }^{1}$ Department of Physical Metallurgy and Materials Testing, Montanuniversität Leoben, Franz-JosefStraße 18, A-8700 Leoben, Austria

${ }^{2}$ MTU Aero Engines GmbH, Dachauer Str. 665, D-80995 Munich, Germany

ahelmut.clemens@unileoben.ac.at, bwilfried.smarsly@mtu.de

Key words: Intermetallics, titanium aluminides, alloy development, properties, processing, applications.

\begin{abstract}
Development and processing of high-temperature materials is the key to technological progress in engineering areas where materials have to meet extreme requirements. Examples for such areas are the aerospace and automotive industries. New structural materials have to be stronger, stiffer and lighter to withstand the extremely demanding conditions in the next generation of aero- and automotive engines. Intermetallic $\gamma$-TiAl based alloys exhibit numerous attractive properties which meet these demands. These properties include high melting point, low density, high specific elastic modulus, good oxidation and burn resistance, and high specific strength up to application temperatures of 700 to $800^{\circ} \mathrm{C}$. Thus, current $\gamma$-TiAl based alloys outperform advanced Ti-based alloys and have the potential to replace heavy Ni-based superalloys.
\end{abstract}

\section{Introduction}

Intermetallic $\gamma$-TiAl-based alloys represent a good example how fundamental and applied research along with industrial development can lead to a new class of advanced engineering materials [1-5]. Due to their attractive properties, $\gamma$-TiAl-based alloys are considered for high-temperature applications in aerospace and automotive industries. Their advantage is mainly seen in low density (3.9 - $4.2 \mathrm{~g} / \mathrm{cm}^{3}$, depending on composition and constitution), high specific yield strength, high specific stiffness, good oxidation resistance, resistance against "titanium fire", and good creep properties up to high temperatures. The variation of the specific yield strength and the specific elastic modulus with temperature of various $\gamma$-TiAl-based alloys in comparison with Ni-base superalloys and Ti- based alloys is shown in Fig. 1.
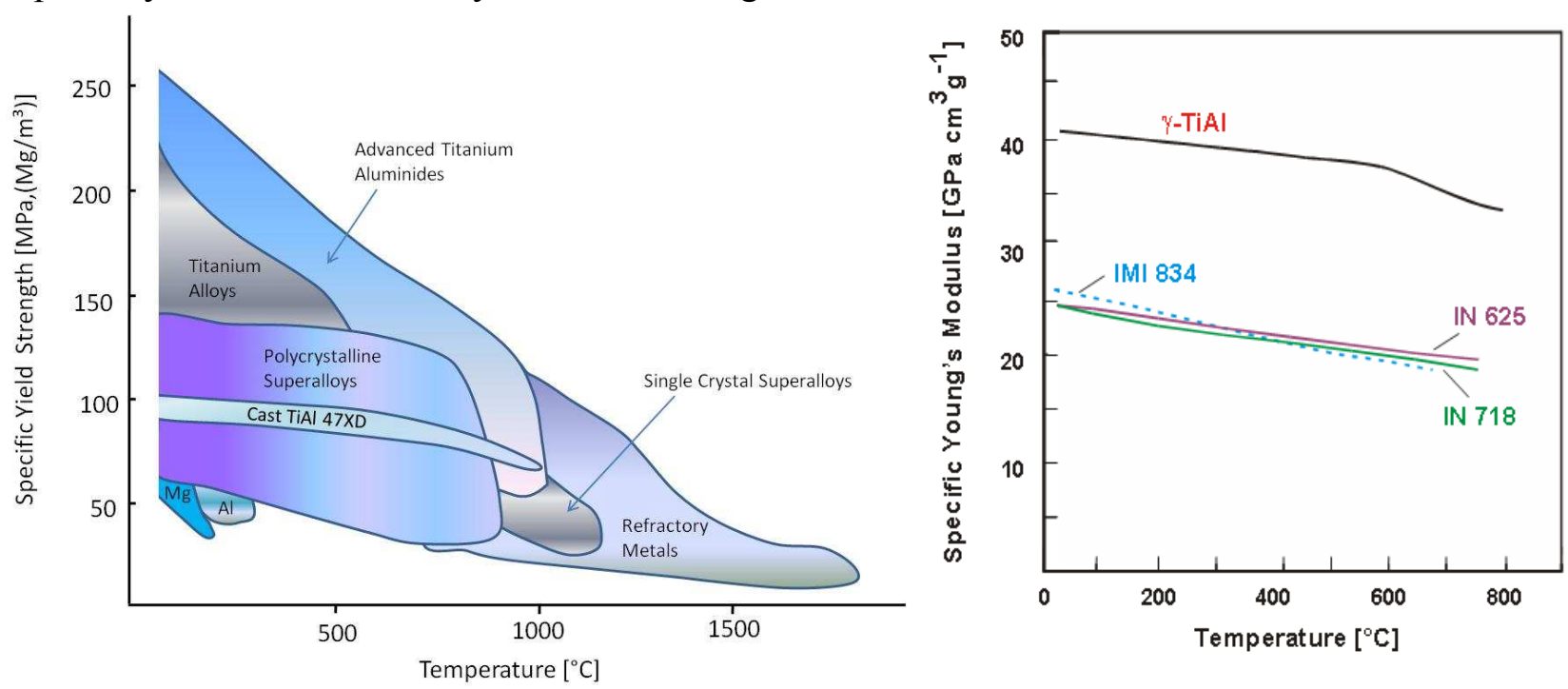

Fig 1: Variation of specific yield strength (left) and specific stiffness (right) with temperature of selected structural materials in comparison with intermetallic titanium aluminide alloys. 
Particularly at temperatures between $600^{\circ} \mathrm{C}$ and $800^{\circ} \mathrm{C} \gamma$-TiAl-based alloys are superior to Ti alloys in terms of their specific strength. Compared to the heavier Ni base alloys, their specific strength is at least similar. In the last years, high-strength $\gamma$-TiAl-based alloys have been developed (Fig. 1). These alloys are characterised by a high content of $\beta$-stabilizing alloying elements, such as $\mathrm{Nb}$ and Mo [6-7]. At room temperature strength levels $>1000 \mathrm{MPa}$ can be achieved by appropriate thermomechanical processing. It is also important to note that the high temperature properties, such as creep resistance, were considerably improved, thus extending the application range of $\gamma$-TiAl-based alloys.

\section{Constitution and Properties of $\boldsymbol{\gamma}$-TiAl Based Alloys}

$\gamma$-TiAl-based alloys of engineering interest consist of $\gamma$-TiAl (ordered face - centered tetragonal L1 $1_{0}$ structure) and $\alpha_{2}-\mathrm{Ti}_{3} \mathrm{Al}$ (ordered hexagonal D0 ${ }_{19}$ structure). In thermodynamic equilibrium the $\gamma / \alpha_{2}-$ volume fraction is controlled by the Al-content and additional alloying elements and typically is in the range of 5 to 20 percent. However, thermo-mechanical processing and heat treatments have a strong influence on the actual $\gamma / \alpha_{2}$-volume fraction in $\gamma$-TiAl-based alloys. In Al-lean alloys containing $\mathrm{Cr}, \mathrm{Nb}$, Mo or $\mathrm{W}$, a significant amount of $\beta(\mathrm{Ti})$ phase with disordered bec structure or its ordered counterpart with B2 structure is often formed. Micro-alloying with B and Si leads to the formation of various types of borides and silicides, because the solubility limit of these elements in $\gamma$-TiAl and $\alpha_{2}-\mathrm{Ti}_{3} \mathrm{Al}$ phase is relatively low.

The ductility and strength of $\gamma$-TiAl based alloys are controlled by chemistry and microstructure. For fine-grained binary alloys, the room temperature elongation to fracture varies with Al-content, exhibiting a maximum at the two-phase composition Ti-48at\%Al. Since low temperature ductility is a major concern for structural applications, $\gamma$-TiAl alloys of engineering importance are based on Ti(45-48)Al $[1,3,8,9]$. However, even at the beginning of the development activities it was recognised that binary two-phase alloys can generally not be used due to their inability to meet requirements such as creep strength and resistance to oxidation. As a consequence, the effect of alloying elements on the mechanical properties of two phase $\gamma$-TiAl-based alloys with specific types of microstructure has been investigated within the framework of extensive research and development programs.

The composition of conventional engineering $\gamma$-TiAl-based alloys, so-called $2^{\text {nd }}$ generation alloys, can be summarized as follows (in at- $\%$ ):

$\mathrm{Ti}-(45-48) \mathrm{Al}-(1-3) \mathrm{X}-(2-5) \mathrm{Y}-(<1) \mathrm{Z}$

where, $\mathrm{X}=\mathrm{Cr}, \mathrm{Mn}, \mathrm{V} ; \mathrm{Y}=\mathrm{Nb}, \mathrm{Ta}, \mathrm{W}, \mathrm{Mo} ; \mathrm{Z}=\mathrm{Si}, \mathrm{B}, \mathrm{C}$.

Generally, the mentioned alloying elements alter the position of the phase boundaries of the Ti Al phase diagram. For example, $\mathrm{Nb}$ and Mo shift the $\alpha$-transus line to the Al rich side, thus narrowing the $(\alpha+\gamma)$ phase field. For a fixed Al content this leads to an increase of the $\alpha$ (and $\alpha_{2}$ ) volume fraction. This effect is exploited in high $\mathrm{Nb}$ and Mo containing alloys where a significant refinement of the microstructure can be achieved [6,7]. $\mathrm{Nb}$ also lowers the stacking fault energy and thus increases the ductility of the alloys at room temperature by increasing the propensity for mechanical twinning [6]. The other alloying elements improve the high temperature properties (resistance to oxidation, creep strength, etc.). Boron is typically used as a grain refining agent. Engineering $\gamma$-TiAl-based alloys of the $2^{\text {nd }}$ generation contain at least one "X"-element and one "Y"-element which improves oxidation and creep resistance. An example of a $2^{\text {nd }}$ generation alloy is Ti-48Al-2Nb-2Cr which was recently introduced as turbine blade material in aero engines [10]. However, like in the case of superalloys currently used, TiAl alloys can contain up to 8 alloying elements. Depending on alloy chemistry and microstructure, these alloys exhibit good workability, medium-to-good tensile properties (Fig. 1), tensile fracture strains in the range of 1 to $3 \%$ at room temperature and fracture toughness values in the range of 10 to $25 \mathrm{MPa} \sqrt{\mathrm{m}}$ [1-3]. However, the 
creep resistance of these alloys seems to limit the maximum application temperature to $700^{\circ} \mathrm{C}$, especially if long-term service is considered. This is probably a direct consequence of thermally activated dislocation processes which make the mechanical behavior of $\gamma$-TiAl alloys strongly ratedependent [9]. Thus, the strength degrades at the low strain rates which normally occur under creep conditions. Additional limitations might arise from microstructural instabilities which are also expected to degrade the creep properties, and from an insufficient oxidation resistance at temperatures exceeding $700^{\circ} \mathrm{C}$ [1-3].

In order to increase the high-temperature capabilities of $\gamma$-TiAl-based alloys, current alloy development programs are focused on high $\mathrm{Nb}$ and Mo containing alloys as well as precipitation hardened alloys $[6,8,9]$. For a large number of these $3^{\text {rd }}$ generation alloys the constitution can be written as:

$\mathrm{Ti}-(42-46) \mathrm{Al}-(0-10) \mathrm{X}-(0 .-3) \mathrm{Y}-(0-1) \mathrm{Z}-(0-0.5 \mathrm{RE})$

where, $\mathrm{X}=\mathrm{Cr}, \mathrm{Mn}, \mathrm{Nb}, \mathrm{a} ; \mathrm{Y}=\mathrm{Mo}, \mathrm{W}, \mathrm{Hf}, \mathrm{Zr} ; \mathrm{Z}=\mathrm{C}, \mathrm{B}, \mathrm{Si}$; RE: rare earth elements.

$\gamma$-TiAl based alloys with $\mathrm{Nb}$ contents in the range of 5 to 10 at $\%$ and small additions of $\mathrm{B}$ and $\mathrm{C}$ are referred to as TNB alloys [5,6]. Another material class are the so-called TNM ${ }^{\mathrm{TM}}$ alloys which contain a balanced concentration of the $\beta$-stabilizers $\mathrm{Nb}$ and Mo. At elevated temperatures these alloys possess a large amount of disordered $\beta$-phase with bcc lattice which improves hot workability. It was demonstrated that TNM alloys can be forged using a conventional forging process $[7,11]$. Post-forging heat-treatments can be attuned to achieve moderate to near zero volume fraction of $\beta$-phase allowing a controlled adjustment of the mechanical properties [11]. Both TNM and TNB alloys exhibit improved strength properties and oxidation resistance when compared with conventional $2^{\text {nd }}$ generation $\gamma$-TiAl-based alloys. For example, room temperature tensile strengths in the range of $800-1100 \mathrm{MPa}$ were reported, along with plastic tensile strains $>2 \%$. The high contents of $\mathrm{Nb}$ and Mo impede diffusion processes in these alloys, thus decreasing the climb rate of dislocations. Whereas this behavior is of advantage with regard to creep and thermal stability, the kinetics of phase transformations and recrystallization processes are slowed down. As a consequence the parameters of heat treatments and hot working operations must be carefully adapted. Improvements in creep strength have also been achieved by $\mathrm{C}$ additions in the range of 0.2 -0.4 at $\%$, where $\mathrm{C}$ forms dispersed $\mathrm{Ti}_{3} \mathrm{AlC}$ precipitates of the perovskite type $[1,6,12]$.

\section{Microstructure and Heat Treatments}

Generally, the influence of microstructure on mechanical properties of $\gamma$-TiAl-based alloys can be summarized as follows: coarse-grained fully lamellar and nearly lamellar microstructures exhibit relatively high fracture toughness and creep resistance, but poor tensile ductility and strength especially at room temperature $[8,9,13]$. Comparably fine-grained equiaxed near gamma and duplex microstructures with only small amounts of lamellar colonies show low fracture toughness and creep resistance but moderate tensile ductility and strength at room temperature and elevated temperatures. This inverse correlation between tensile properties and resistance to fracture (fracture toughness) requires a careful selection of the microstructure which makes microstructural optimisation important for achieving balanced engineering properties. For engineering $\gamma$-TiAl-based alloys with compositions given in eq. (2), the optimum balance between fracture toughness and creep resistance on one side and room temperature tensile ductility/strength on the other side is expected for microstructures composed of relatively small lamellar colonies (50 to $100 \mu \mathrm{m}$ in diameter) exhibiting narrow lamellar spacing and a small volume fraction of globular $\gamma$ and $\beta$ grains [11]. In order to realise these designed microstructures by using industrial annealing furnaces, the transformation behavior of $\gamma$-TiAl alloys must be known exactly, e.g. the variation of the $\alpha$-transus temperature within the limits of the specified composition range. 


\section{Thermo-mechanical Processing of $\gamma$-TiAl Based Alloys}

Hot-working of $\gamma$-TiAl-based alloys is conducted exclusively above their brittle-to-ductile transition temperature, i.e. at temperatures considerably higher than $700^{\circ} \mathrm{C}$ and can be divided in primary and secondary hot-working steps. The aim of primary hot-working of cast ingots is to convert (or breakdown) the coarse-grained microstructure into a fine-grained and uniform microstructure suitable for subsequent wrought processing or heat treatments. This is usually accomplished by employing hot-working parameters at which dynamic recrystallization is prevalent and macroscopic as well as microscopic damage can be neglected, i.e. at temperatures between the eutectoid temperature and the $\alpha$-transus temperature and at relatively low deformation rates. During the last decade several wrought $\gamma$-TiAl alloys with complex alloy compositions have been developed [13,14]. These alloys exhibit excellent mechanical properties, but show narrow processing windows. Therefore, these alloys can be forged only under isothermal conditions. However, isothermal forging of $\gamma$-TiAl based alloys must be performed at high temperatures, requiring special dies and environmental conditions which increase manufacturing costs. Therefore, $\mathrm{Nb}$ and Mo containing $\mathrm{TNM}^{\mathrm{TM}}$ alloys have been developed which are equally suited for hot-die forging under near conventional conditions [7,11] and isothermal forging [15].

Concerning forging operations of $\gamma$-TiAl based alloys on an industrial scale, little is found in the open literature. Most of the published work was carried out on ingot breakdown routes and the kinetics associated with microstructural refinement and chemical homogenization of the cast microstructure. An example of the successful combination of different hot-forming processes is the manufacture route of TiAl valves as described in [16]. Here, multi-step extrusion, hot-bulging and quasi-isothermal near-net-shape forging have been employed. The TiAl valves are entirely produced using industrial production equipment. The valves have a homogeneous fine-grained microstructure and have been successfully tested in engines.

Isothermal closed-die forging of high-pressure compressor blades was reported by Appel et al. [17]. The use of extruded TiAl bar with a refined microstructure as starting material reduced the susceptibility to cracking during hot-working. More than 200 blades were forged in this development program using the optimum processing parameters obtained from laboratory compression tests.

Closed impression die forging of a $\gamma$-TiAl based alloy has been evaluated for the manufacture of complex shaped demonstration components, including subscale discs and turbine blades. A refined, uniform billet material for the component forging operation was obtained through ingot conversion by isothermal forging. From this billet with near gamma microstructure pre-forms of two different geometries for subsequent blade forging were produced by machining. The closed-die forging operation was accomplished in a single step with isothermal forging temperatures between $1165^{\circ} \mathrm{C}$ and $1205^{\circ} \mathrm{C}$. The result of the forging trials were prototype turbine blades with excellent geometry tolerances. Further details concerning process parameters, alloys used, microstructure of the forged parts and post-forging heat treatments are given in [18].

Insight into the microstructural processes and the corresponding flow behaviour during forging have been published by Millet et al. [19] and Brooks et al. [20], who studied isothermal forging of gas turbine airfoils. In their work, a flow stress model was incorporated into a finite element code, allowing specification of the forging process itself, the microstructural evolution and the flowsoftening behavior of $\gamma$-TiAl during hot-working.

The manufacture of TiAl blades has also been reported by Tetsui et al. [21]. Here, a Ti-42Al$5 \mathrm{Mn}$ alloy is heated to about $1300^{\circ} \mathrm{C}$ in the $(\alpha+\beta)$ region and then forged during cooling on a conventional facility. Subsequently, the blade was machined from the forged square by conventional milling and a chip-free technique.

Recently, the technical feasibility of manufacturing a turbine blade by means of a near conventional hot-die process has been demonstrated [11,22]. Subsequent, two-step heat treatments were conducted to adjust balanced mechanical properties, i.e. a sufficiently high plastic fracture strain at room temperature and good creep properties at elevated temperatures [11]. 


\section{Applications of $\boldsymbol{\gamma}$-TiAl Based Alloys in Automotive and Aero Engines}

World-wide the demand for reduced fuel consumption, emissions and noise in motor vehicles is steadily increasing. For example, regulations which will limit emissions from mid- to large size Diesel engines will soon be enforced in Europe and the USA. The European automotive industry is meeting this challenge by further downsizing of their conventional combustion engines $[1-4,13,23]$. Additionally, efficiency and engine performance will be enhanced by increasing combustion gas temperatures up to $850^{\circ} \mathrm{C}$ (Diesel engine) and to $1050^{\circ} \mathrm{C}$ (Otto engine) with gas pressures and engine revolutions per minute are simultaneously rising. As a consequence, the requirements for oscillating and rotating components operating at high temperatures are steadily increasing. Thus, new light-weight, high temperature materials and cost-effective production techniques must be developed and applied. In this context $\gamma$-TiAl based alloys exhibit a promising combination of low density and high strength at elevated temperatures.

In 1999 the first commercial application of $\gamma$-TiAl based alloys was announced. Mitsubishi has implemented TiAl turbocharger wheels in their Lancer 6 sports car [24]. The turbine wheels were produced by means of the LEVICAST process, a modification of the lost wax precision casting method as well as by centrifugal casting. It should be noted that in Europe ABB has equipped the two Diesel engines of an operational high-speed ferry with $\gamma$-TiAl turbocharger wheels. This ferry has been in successful operation with the TiAl wheels for over two years, for a total of over 4,000 hours service time [25]. Engine valves appear to be another suitable application for $\gamma$-TiAl based alloys [1-3,13]. In 2002, the commercial production of wrought processed high-performance $\gamma$-TiAl valves for racing car application has started [26]. The processing route is a variant of multi-step extrusion. Further production steps include precision machining and coating.

There are at least three major payoff areas for $\gamma$-TiAl-based alloys in advanced aero engines and gas turbines [1,2,13,27]: (a) $\gamma$-TiAl has a specific elastic stiffness $50 \%$ greater than structural materials commonly used in aircraft engines. The higher specific stiffness (E/ $\rho$ ) also shifts acoustically excited vibrations towards higher frequencies, which is usually beneficial for structural components, e.g., compressor and turbine blades and parts within the exhaust nozzle area. (b) The good creep resistance of advanced $\gamma$-TiAl-based alloys in the temperature regime of 600 to $800^{\circ} \mathrm{C}$, enables the substitution of Ni-based alloys (twice the density as $\gamma$-TiAl alloys) for certain applications. (c) The high fire resistance of $\gamma$-TiAl-based alloys (nearly as resistant as Ni-based alloys) can enable the substitution of heavy and expensive fire-resistant designed Ti-based alloys in some components. Recently, an US aero engine manufacturer announced the initiation of investment cast $\gamma$-TiAl blades in the low-pressure turbine. Certification and flight tests with TiAl equipped engines have been conducted successfully and begin of the regular service for passenger transport is expected soon [10].

\section{Concluding Remarks}

Intermetallic $\gamma$-TiAl-based alloys are considered as a very important candidate material for advanced applications in aerospace, automotive and related industries. World-wide research and development on $\gamma$-TiAl alloys have led to a better understanding of the fundamental influence of alloy composition and microstructure on mechanical properties and processing behavior. In the last years industry has started to use of this new class of light-weight high-temperature materials. In particular, all major aircraft and automotive engine manufacturers are advancing the qualification and introduction of $\gamma$-TiAl components. $\gamma$-TiAl-based alloys can be processed using advanced metallurgical methods - a factor, which is decisive for these specific materials to be economically competitive with other state-of-the-art materials. In current $\gamma$-TiAl-based alloys balanced properties like room temperature ductility, fracture toughness, high-temperature strength, creep and oxidation resistance can be achieved. 


\section{References}

[1] Gamma Titanium Aluminides 2003, edited by Y-W. Kim, H. Clemens and A. Rosenberger, The Minerals, Metals and Materials Society (TMS), Warrendale, PA, USA (2003).

[2] Structural Aluminides for Elevated Temperature Applications, edited by Y-W. Kim, D. Morris, R. Yang, and C. Leyens, The Minerals, Metals and Materials Society (TMS), Warrendale, PA, USA (2008).

[3] Titanium and Titanium Alloys, edited by M. Peters and C. Leyens, Wiley-VCH, Weinheim, Germany (2003).

[4] H. Clemens, F. Appel, A. Bartels, H. Baur, R. Gerling, V. Güther, and H. Kestler, in: Ti-2003 Science and Technology, edited by G. Lütjering and J. Albrecht, Wiley-VCH, Weinheim, Germany, (2004), p. 2123.

[5] F. Appel, and M. Oehring, in [3], p. 89.

[6] F. Appel, M. Oehring and R. Wagner: Intermetallics 8 (2000), p. 1283.

[7] H. Clemens, W. Wallgram, S. Kremmer, V. Güther, A. Otto, and A. Bartels: Adv. Eng. Mater. 10 (2008), p. 707.

[8] Y-W. Kim: J. Met. 46 (1994) p. 30.

[9] F. Appel and R. Wagner: Mater. Sci. Eng. R22 (1998), p.187.

[10] T. Kelly: Presentation at the Symposium on "Structural Aluminides for Elevated Temperature Applications", TMS 2008 Annual Meeting, New Orleans, LA, USA (March 9-13, 2008).

[11] W. Wallgram, T. Schmoelzer, G. Das, V. Güther, and H. Clemens: Int. J. Mat. Res. 100 (2009), p. 1021.

[12] C. Scheu, E. Stergar, M. Schober, L. Cha, H. Clemens, A. Bartels, F.-P. Schimansky, and A. Cerezo: Acta Mater. 57 (2009), p. 1504.

[13] H. Clemens and H. Kestler: Adv. Eng. Mater. 2 (2000), p. 551.

[14] F. Appel, J. D. H. Paul, M. Oehring, H. Clemens, F.D. Fischer: Z. Metallkd. 95 (2004) p. 585.

[15] N. Rizzi: Presentation at the Symposium "Structural Aluminides for Elevated Temperature Applications", TMS 2008 Annual Meeting, New Orleans, LA, USA (March 9-13, 2008).

[16] S. Knippscheer, G. Frommeyer, H. Baur, R. Joos, M. Lohmann, O. Berg, H. Kestler, N. Eberhardt, V. Güther, and A. Otto, in Materials for Transportation Technologies, edited by P. J. Winkler), Wiley-VCH, Weinheim, Germany (2000), p. 111.

[17] F. Appel, U. Brossmann, U. Christoph, S. Eggert, P. Janschek, U. Lorenz, J. Müllauer, M. Oehring, and J.D.H. Paul: Adv. Eng. Mater. 2 (2000), p. 699.

[18] D. U. Furrer, R. R. Hoffman and Y-W. Kim, in Gamma Titanium Aluminides, edited by Y-W. Kim, R. Wagner and M. Yamaguchi, TMS, Warrendale, PA, USA (1995), p. 611.

[19] J.F.C. Millet, J.W. Brooks and Z.M. Zu: Mater. Sci. Technology 15 (1999) p. 697.

[20] J.W. Brooks, T.A. Dean, Z.M. Zu and E. Wey: Mater. Process. Techn. 80/81 (1998), p. 149.

[21] T. Tetsui, K. Shindo, S. Kobayashi, and M. Takeyama: Scripta Mater. 47 (2002), p. 299.

[22] S. Kremmer, H.F Chladil, H. Clemens, A. Otto, and V. Güther in: Ti-2007 Science and Technology, edited by M. Niinomi, S. Akiyama, M. Hagiwari, M. Ikeda, and K. Maruyama, The Japan Institute of Technology, Tokyo, Japan (2008), p. 989.

[23] H. Baur, R. Joos, W. Smarsly, and H. Clemens: in Intermetallics and Superalloys, edited by D. G. Morris, S. Naka and P. Caron, Wiley-VCH, Weinheim, Germany (2000), p.384.

[24] T. Tetsui: in Gamma Titanium Aluminides 1999, edited by Y-W. Kim, D. M. Dimiduk and M. H. Loretto, TMS, Warrendale, PA, USA (1999), p. 15.

[25] P. A. McQuay: in Structural Intermetallics 2001, edited by K. Hemker, D. Dimiduk, H. Clemens, R. Darolia, H. Inui, J. Larsen, V. Sikka, M. Thomas, and D. Wittenberger, TMS, Warrendale, PA, USA (2001), p. 83.

[26] Information on http://www.mwracing.eu

[27] W. Smarsly, H. Baur, G. Glitz, H. Clemens, T. Khan, and M. Thomas: in Structural Intermetallics 2001, edited by K. Hemker, D. Dimiduk, H. Clemens, R. Darolia, J. Larsen, V. Sikka, M. Thomas, and D. Wittenberger, TMS, Warrendale, PA, USA (2001), p. 25. 